\title{
Dynamic Modeling of Electric Springs
}

\author{
Nilanjan Ray Chaudhuri, Member, IEEE, Chi Kwan Lee, Member, IEEE, Balarko Chaudhuri, Senior \\ Member, IEEE, and S.Y.Ron Hui, Fellow, IEEE
}

\begin{abstract}
The use of 'Electric Springs' is a novel way of distributed voltage control while simultaneously achieving effective demand-side management through modulation of noncritical loads in response to the fluctuations in intermittent renewable energy sources (e.g. wind). The proof-of-concept has been successfully demonstrated on a simple $10 \mathrm{kVA}$ test system hardware. However, to show the effectiveness of such electric springs when installed in large numbers across the power system, there is a need to develop simple and yet accurate simulation models for these electric springs which can be incorporated in large-scale power system simulation studies. This paper describes the dynamic simulation approach for electric springs which is appropriate for voltage and frequency control studies at the power system level. The proposed model is validated by comparing the simulation results against the experimental results. Close similarity between the simulation and experimental results gave us the confidence to use this electric spring model for investigating the effectiveness of their collective operation when distributed in large number across a power system. Effectiveness of an electric spring under unity and non-unity load power factors and different proportions of critical and non-critical loads is also demonstrated.
\end{abstract}

Index Terms-Demand side management, reactive power control, electric springs

\section{INTRODUCTION}

$\mathrm{T}$ HE role of demand side management is going to be critical once the penetration of renewable energy sources becomes significant [1, 2]. This would bring about a paradigm shift from the traditional centralized control of hundreds of power plants to match the demand to decentralized control of millions of loads to balance the supply (generation). Although the concept is well understood and demonstrated for small prototypes (e.g. a smart refrigerator), the challenge is to coordinate the contribution from millions of loads to achieve a desired goal at the system level e.g. overall frequency regulation [1]. The techniques reported in the literature mostly rely on remote communication to achieve this [3]. Several complex algorithms have been proposed to ensure coordination among loads [4-7].

The use of 'Electric Springs' has recently been proposed as a novel and simple way of distributed voltage control while simultaneously enabling effective demand-side management without any need for communication. This is achieved through modulation of non-critical loads in response to the fluctuations in intermittent renewable energy sources (e.g. wind) [8, 9]. Electric springs (ES) inject a controllable voltage in series with the so called non-critical loads (which are less sensitive to voltage fluctuations) in order to regulate the voltage across the critical (voltage sensitive) loads. Thus alongside voltage control, the power consumed by the noncritical load is modulated according to the input power resulting in frequency regulation. Unlike a Dynamic Voltage Restorer (DVR) which is installed in series in the distribution line an ES is connected in series with the non-critical load with a single point of connection to the distribution network. The proof of concept has been successfully demonstrated on a simple $10 \mathrm{kVA}$ test system hardware comprising of a single smart load with an ES [8, 9]. The next challenge is to show the effectiveness of ES at the system level when several of these are distributed across the network. It is therefore required to develop a simple yet accurate model for the ES which can be incorporated into large scale system simulation models which is the focus of this paper. Unlike [9], the objective here is to validate the simplified dynamic model by comparing the simulation results against the experimental results under a range of scenarios. This model can then be used by power engineers to analyze power systems with large number of electric springs embedded.

In this paper, an averaged simulation model for an ES is proposed for use in power system studies [10]. Simulation results with the proposed averaged model are benchmarked against those obtained from the experiments. Close similarity between the simulation and experimental results gave us the confidence to use this electric spring model for investigating the effectiveness of their collective operation when distributed in large number across a power system. Discrepancies between the simulation and experimental results are accounted for and it is concluded that those discrepancies can be taken care of at the expense of significant increase in simulation (computation) complexities. The dynamic model of the ES was validated under different load power factors and also different proportion of critical and non-critical loads. It is shown that the proposed dynamic model is capable of dealing with resistive-inductive (RL) loads over a range of load power factors and study the effectiveness of an ES under different proportion of critical and non-critical loads.

\section{BASIC OPERATION OF ELECTRIC SPRINGS}

The use of "Electric Springs" is a recently introduced approach to distributed voltage control through voltage compensators connected in series with individual non-critical loads that are less sensitive to voltage fluctuations. These compensators inject a series voltage in quadrature (either lead or lag) with the current flowing through them in order to regulate the voltage across the point of common coupling where critical (i.e. voltage sensitive) loads are connected. The approach is fundamentally different from the traditional way 
of shunt voltage control through SVC, STACOM etc. which are connected at the point-of-common-coupling (PCC) to control the voltage across several loads [11]. One potential advantage of the proposed approach is it could contribute to frequency control by modulating the voltage and hence the power consumed by the non-critical load while regulating the voltage across the critical loads. The non-critical loads are connected in series with the ES to form a smart load as shown in Fig. 1.

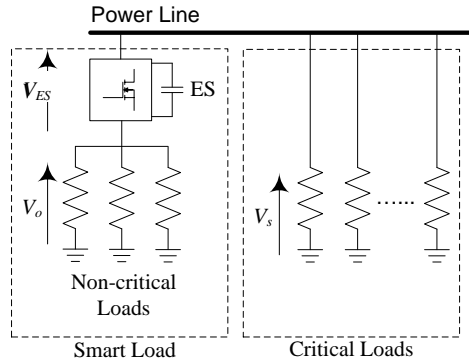

Fig. 1: Smart loads and critical loads in future smart grids

For reactive power control, an electric spring (ES) injects a compensation voltage $V_{E S}$ in quadrature with the current through it. The current $I_{o}$ can either lead the voltage $V_{E S}$ by $90^{\circ}$ (capacitive mode for voltage support) or lag $V_{E S}$ by $90^{\circ}$ (inductive mode for voltage suppression). The power converter circuit of the ES could simply be a two-level inverter as shown in Fig. 2.

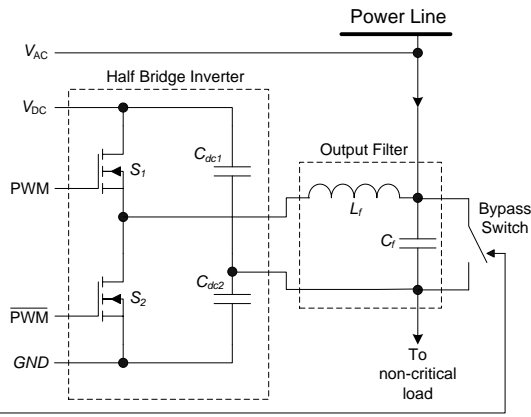

Fig. 2: Schematic of a single phase half bridge power inverter

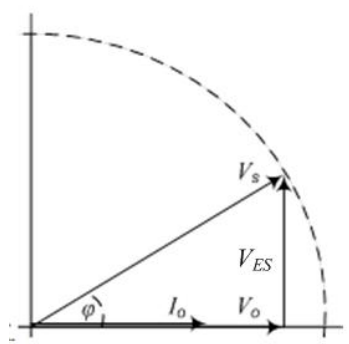

(a)

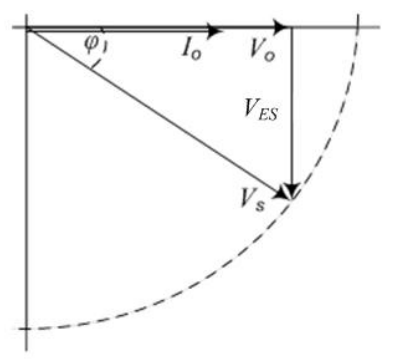

(b)
Fig. 3: Phasor digrams for inductive and capacitive modes of operation of an ES

Thus, an ES can inject both inductive and capacitive reactive power to the power line similar to the conventional reactive power controller (RPC) [12, 13]. For ease of understanding, both the critical and non-critical loads are assumed to be purely resistive although the underlying principle is still applicable as long as these loads are voltage dependent. Under this assumption, the phasor diagrams for inductive and capacitive modes of operation are shown in Fig. 3. The electric spring differentiates itself from a traditional RPC by adopting an "input-voltage control". By regulating the input voltage $V_{s}$ and letting the output voltage $V_{o}$ to fluctuate dynamically (i.e. a new input-voltage control), an ES would (i) provide voltage support and (ii) simultaneously modulate the non-critical load power to follow the power generated. Such a subtle change in the control strategy of a traditional RPC from output control to input control offers new possibility of simultaneous voltage and frequency control enabling effective demand side management.

\section{CONTROL OF ELECTRIC SPRINGS}

Fig. 4 shows a complete control block diagram of an electric spring. It consists of two closed loop controller including an AC voltage controller to regulate the power line voltage and a DC bus voltage controller to regulate the inverter dc bus voltage. The individual transfer function of the digital PI controller in discrete from is expressed as

$$
u(t)=u(t-1)+K_{P}[e(t)-e(t-1)]+K_{p} \frac{T_{S}}{T_{i}} e(t)
$$

where $u(t), u(t-1)$ and $e(t), e(t-1)$ are the transfer function output and error input of the controller at the present and pass sampling, respectively. $K_{p}$ is the proportional gain constant, $T i$ is the integral time constant and $T_{s}$ is the sampling time of the controller.

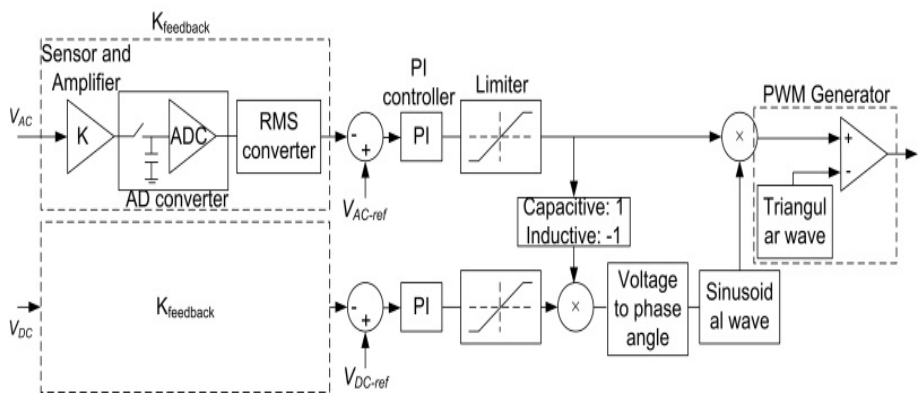

Fig. 4: Block diagram for electric spring control

The output of the PI compensator driving the AC line voltage error to zero decides the modulation index. The DC link voltage controller decides the phase angle of the injected voltage. When the angle of the reference sinusoidal voltage is measured with respect to the system current flowing through the non-critical voltage, it is going to be very close to 90 degrees. The deviation from 90 degree phase angle is decided by the real power exchange with the DC bus. 


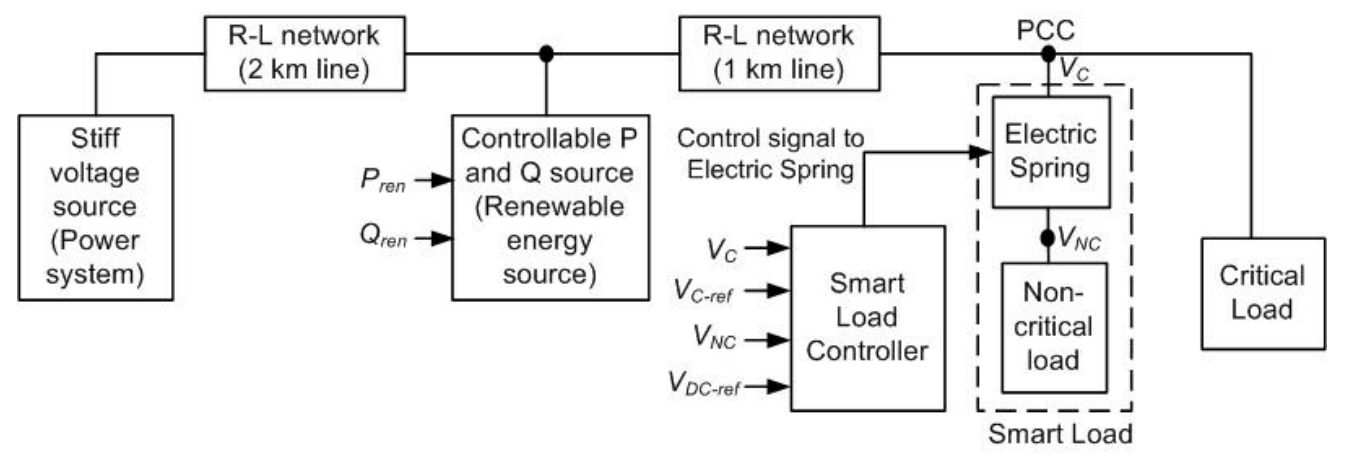

Fig. 5: Block diagram of the test system with Electric Spring

\section{DYNAMIC SIMULATION}

\section{A. Test system model}

Fig. 5 shows the block diagram of the overall test system which is modeled in MATLAB/SIMULINK. A voltage source is used to model the bulk power system. The active and reactive power fluctuation from the renewable energy source $\left(P_{\text {ren }}, Q_{\text {ren }}\right)$ is modeled by a controllable current injection at the point of connection with the network. The amplitude of the current is determined by the active and reactive power exchanged. Two segments of the network are modeled by lumped R-L equivalent. The smart load comprising the ES and a resitive non-critical load in series and the critical load are connected at the PCC. The smart load controller controls the voltage injected by the ES in series with the non-critical load. For simplicity, both the critical and non-critical loads are assumed to be purely resistive to start with. Towards the end of Section V, simulation results for resitive-inductive (RL) loads with 0.95 (lagging) power factor is presented to show the validity of the model.

\section{B. Electric spring power circuit}

The power circuit of the Electric Spring and that of the Smart Load including the Electric Spring are shown in Fig.6 and Fig. 7, respectively. $V_{E S}$ represents the voltage injected by the Electric Spring and $L_{f}, R_{f}$ and $C_{f}$ are the inductance, resistance and capacitance of the output filter at the inverter terminal. Neglecting inverter losses, the real power balance between the AC and the DC side of the converter results in:

$$
\begin{gathered}
P_{d c}=\frac{1}{2}\left(C_{d c 1}+C_{d c 2}\right) \frac{d\left(V_{d c}{ }^{2}\right)}{d t}= \\
\left(C_{d c 1}+C_{d c 2}\right) V_{d c} \frac{d V_{d c}}{d t}=I_{i n j}^{2} R_{f}
\end{gathered}
$$

Applying KVL on the AC side of the inverter:

$$
V_{a}-V_{E S}=L_{f} \frac{d I_{\text {inj }}}{d t}+R_{f} I_{i n j}
$$

and

$$
V_{c}=R_{N C} I_{E S 1}+V_{E S}
$$

Applying KCL on the AC side:

$$
I_{E S 1}+I_{i n j}=C_{f} \frac{d V_{E S}}{d t}
$$

From Fig. 2 and 6a, the terminal voltage $V_{a}$ at the HalfBridge module can be written as:

$$
V_{a}(t)=\left(\frac{V_{d c}}{2}\right) P W M-\left(\frac{V_{d c}}{2}\right) \overline{P W M}
$$

Note that ' $P W M$ ' is the switching function commanding the switches to turn on/off. Let, $T_{s}$ be the switching period and $h$ the order of harmonics. Decomposing into fundamental and high frequency harmonic components we get:

$V_{a}(t)=V_{1 a}(t)+\sum_{h=1}^{\infty} a_{h} \cos \left(\frac{2 \pi h}{T_{s}} t\right)+b_{h} \sin \left(\frac{2 \pi h}{T_{s}} t\right)$

Hence the terminal voltage averaged over one switching period can be written as:

$\bar{V}_{a}(t)=\frac{1}{T_{s}} \int_{0}^{T_{s}} V_{1 a}(\tau) d \tau+\sum_{h=1}^{\infty} a_{h} \cos \left(\frac{2 \pi h}{T_{s}} t\right)+b_{h} \sin \left(\frac{2 \pi h}{T_{s}}\right)$

The first term is the fundamental frequency $(50 \mathrm{~Hz})$ component of $V_{a}(t)$ averaged over one switching time period. Assuming the switching frequency is much higher than the fundamental frequency, this term is effectively a DC component. The second term would result in a sinusoidal function with high frequency. From (2), the current $\mathrm{I}_{i n j}$ at the output of the inverter can be expressed as:

$$
\begin{gathered}
L_{f} \frac{d I_{i n j}}{d t}+R_{f} I_{i n j}=\frac{1}{T_{s}} \int_{0}^{T_{S}} V_{1 a}(\tau) d \tau+\sum_{h=1}^{\infty} a_{h} \cos \left(\frac{2 \pi h}{T_{s}} t\right) \\
+b_{h} \sin \left(\frac{2 \pi h}{T_{s}} t\right)-V_{E S}
\end{gathered}
$$

Note that the current $I_{i n j}$ produced by the imposed voltage would witness a sharp attenuation in harmonics due to the low pass characteristics of the inductor $\mathrm{L}_{\mathrm{f}}$. Therefore, the current response $\overline{I_{l n j}}$ due to the fundamental frequency component of the voltages can be expressed as:

$$
L_{f} \frac{d \overline{I_{\text {lnj }}}}{d t}+R_{f} \overline{I \imath{ }^{\prime} \jmath}=\frac{1}{T_{S}} \int_{0}^{T_{S}} V_{1 a}(\tau) d \tau-V_{E S}
$$

The half bridge inverter is thus represented by a fundamental frequency voltage source with voltage: 


$$
V_{1 a}(t)=\frac{V_{d c}}{2} m(t)
$$

where, $m(t)=M \sin (2 \pi 50 t+\theta)$ is the modulation index and $V_{D C}$ is the DC link voltage.

The state-space averaged model of the Electric Spring can be derived as follows:

Rearranging (1)-(4) and (10) and removing the superbar for the sake of convenience, we can get the state-space averaged model as:

$$
\begin{aligned}
\frac{d I_{i n j}}{d t} & =-\left(\frac{R_{f}}{L_{f}}\right) I_{i n j}+\frac{1}{2}\left(\frac{m}{L_{f}}\right) V_{d c}-\left(\frac{1}{L_{f}}\right) V_{E S} \\
\frac{d V_{E S}}{d t} & =\left(\frac{1}{C_{f}}\right) I_{i n j}+\left(\frac{1}{R_{N C} C_{f}}\right) V_{c}-\left(\frac{1}{R_{N C} C_{f}}\right) V_{E S} \\
\frac{d V_{d c}}{d t} & =\left(\frac{R_{f}}{C_{d c 1}+C_{d c 2}}\right)\left(\frac{I_{i n j}{ }^{2}}{V_{d c}}\right)
\end{aligned}
$$

From (12), it can be seen that the state-space averaged model is non-linear. Neglecting the DC bus dynamics, we can express this with a set of linear time-invariant equations:

$\left(\begin{array}{c}\frac{d I_{i n j}}{d t} \\ \frac{d V_{E S}}{d t}\end{array}\right)=\left(\begin{array}{cc}-\left(\frac{R_{f}}{L_{f}}\right) & -\left(\frac{1}{L_{f}}\right) \\ \left(\frac{1}{C_{f}}\right) & -\left(\frac{1}{R_{N C} C_{f}}\right)\end{array}\right)\left(\begin{array}{c}I_{i n j} \\ V_{E S}\end{array}\right)+\left(\begin{array}{c}\frac{1}{2}\left(\frac{1}{L_{f}}\right) \\ \left(\frac{1}{R_{N C} C_{f}}\right)\end{array}\right)\left(\begin{array}{c}m V_{d c} \\ V_{c}\end{array}\right)$

The averaged circuit model is shown in Fig. 6. Further details of state-space averaging can be found in [10]. Note that the DC link dynamics is not considered, i.e. $V_{D C}=V_{D C \text {-ref }}$ is assumed.

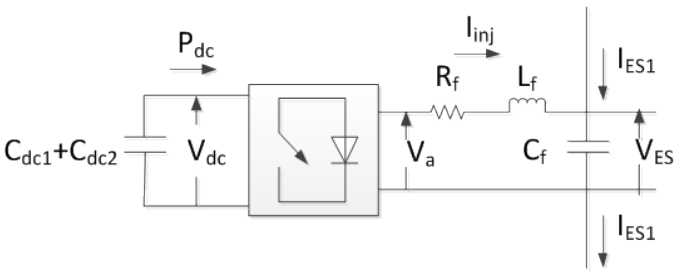

Fig. 6: Power circuit of Electric Spring

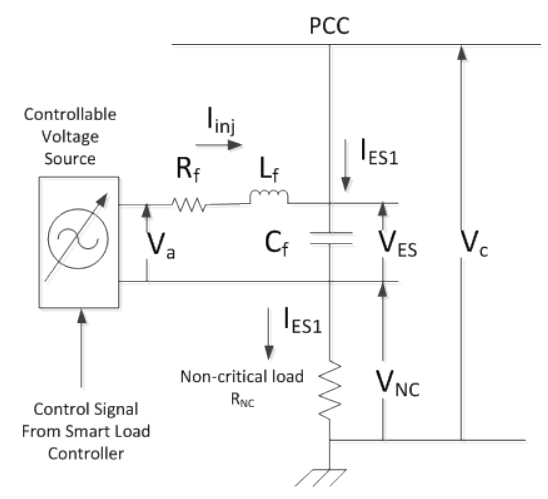

Fig. 7: Model for the power circuit of Smart Load and Electric Spring

It should also be noted that, the reactance of the filter capacitor $C_{f}$ is very high for the fundamental frequency and was neglected for system level simulations. Also, $V_{E S}$ and $V_{a}$ are almost in the same phase as the real power exchange through the inverter is negligibly small. For a system level simulation these arguments are valid and therefore simplifies the control law as mentioned below.

\section{Electric Spring Controller}

A block diagram of the ES controller modeled in MATLAB/SIMULINK is shown in Fig. 8. Since the DC bus dynamics and the losses are neglected, the converter only exchanges reactive power with the AC system. Thus, the phase angle of the injected voltage is \pm 90 degree (depending on the sign of the error between the reference and measured value of $V_{C}$ ) with respect to $\rho$, the phase angle of $I_{E S 1}$. As shown in Fig. 8, a single-phase phase locked loop (PLL) is used to determine the phase angle of $I_{E S 1}$.

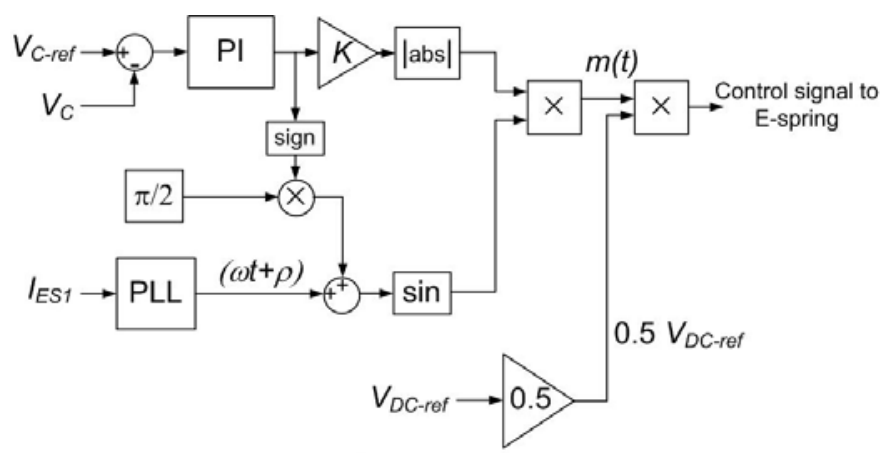

Fig. 8: Block Diagram for Electric Spring Controller

The magnitude of the modulation index $(M)$ is determined from the output of a PI compensator which drives the difference between reference PCC voltage $\left(V_{C-\text { ref }}\right)$ and measuerd PCC voltage $\left(V_{C}\right)$ to zero. A scale factor $(K)$ is used to limit the output of the PI controller within \pm 1 . Note that the PI controller is a discrete controller with a sampling time of $20 \mathrm{~ms}$. The control signal is derived by multiplying the product of the modulation index magnitude $(M)$ and the phase shifted sinusoidal signal by half of the DC link voltage which is assumed to be the same as the DC link voltage reference $\left(V_{D C-r e f}\right)$.

\section{Noteworthy Points}

During dynamic conditions, the DC link voltage fluctuates. Depending on the DC link capacitance and the bandwidth of the DC link voltage control loop, the converter would exchange real power with the grid. The SIMULINK model neglects the DC link dynamics and the converter losses. Therefore, it is expected that there would be certain deviations between the dynamic performances of the model and the hardware test system.

The phasor diagrams in Fig. 3 also give rise to some important insights regarding the steady state values of the ES voltage. It is clear that there can be multiple solutions to $V_{a}$ in order to obtain the same value of the reference voltage $V_{\mathrm{s}}$. Since the convergence of the magnitude of this voltage depends on the both the control loops (used to control $V_{\text {dc }}$ and $V_{\mathrm{s}}$ ) shown in

Fig. 4; the modeling assumptions described above could lead to a different steady state value of $V_{\mathrm{s}}$. 


\section{EXPERIMENTAL VALIDATION}

A schematic overview of the experimental setup is shown in Fig. 9. It comprises of a $90 \mathrm{kVA}$ inverter acting as a controlled power source. A separate $10 \mathrm{kVA}$ inverter is used to emulate an intermittent renewable energy source capable of injecting variable active and/or reactive power which causes the voltage across the critical load to fluctuate. Both critical and non-critical loads are represented by resistors. Here the loads were considered to be resistive although they do not have to be necessarily resistive. The use of the ES for inductive and capacitive non-critical loads has been practically demonstrated in [14].

Distribution lines are represented by standard network boxes. The parameters used for the system and the electric spring (ES) are summarized in Table I and Table II, respectively. Instantaneous voltage and current at different nodes of setup are recorded through a data acquisition system. A photograph of the experimental set up at the Maurice Hancock Smart Energy Laboratory at Imperial College London is shown in Fig. 10.

Table I Detailed System Specifications

\begin{tabular}{|l|l|}
\hline \multicolumn{2}{|c|}{ System and Loads } \\
\hline Nominal Phase Voltage $\left(V_{1}\right):$ & $220 \mathrm{Vac}$ \\
\hline Non-critical Load Resistance $\left(R_{a}\right):$ & $50.5 \Omega$ \\
\hline Other/Critical Load Resistance $(R):$ & $53.0 \Omega$ \\
\hline
\end{tabular}

\begin{tabular}{|l|l|l|}
\hline \multicolumn{3}{|c|}{ Network Box } \\
\hline Distance & Resistance $(\Omega)$ & Inductance $(\mathrm{mH})$ \\
\hline $1 \mathrm{~km}$ & $0.1 \Omega$ & $1.22 \mathrm{mH}$ \\
\hline $2 \mathrm{~km}$ & $0.1 \Omega$ & $2.4 \mathrm{mH}$ \\
\hline
\end{tabular}

\begin{tabular}{|l|l|}
\hline \multicolumn{2}{|c|}{ 90KVA Power Source } \\
\hline Open Circuit Voltage $\left(E_{g}\right):$ & $430 \mathrm{~V}$ \\
\hline Short Circuit KVA $(S S C):$ & $36 \mathrm{KVA}$ \\
\hline Short Circuit Impedance $\left(Z_{g}\right):$ & 5.1 \\
\hline Transformer Reactance Ratio $(X / R):$ & 10 \\
\hline Equivalent Output Resistance $\left(R_{g}\right):$ & $0.51 \Omega$ \\
\hline Equivalent Output Inductance $\left(L_{g}\right):$ & $16.3 \mathrm{mH}$ \\
\hline
\end{tabular}

\begin{tabular}{|l|l|l|}
\hline \multicolumn{3}{|c|}{ Renewable Energy Source Simulator } \\
\hline & $\begin{array}{l}\text { Active Power } \\
\text { (W) } \\
\text { injected to the } \\
\text { grid }\end{array}$ & $\begin{array}{l}\text { Reactive power } \\
\text { (Var) } \\
\text { injected to the gird }\end{array}$ \\
\hline $\begin{array}{l}\text { Steady state conditions } \\
@_{1}=220 V a c\end{array}$ & $250 \mathrm{~W}$ & 467Var (inductive) \\
\hline $\begin{array}{l}\text { Pre-recorded Active and } \\
\text { Reactive Power Profile }\end{array}$ & $250 \mathrm{~W}$ & $\begin{array}{l}\text { Reactive Power } \\
\text { Profile (see Fig.16) }\end{array}$ \\
\hline
\end{tabular}

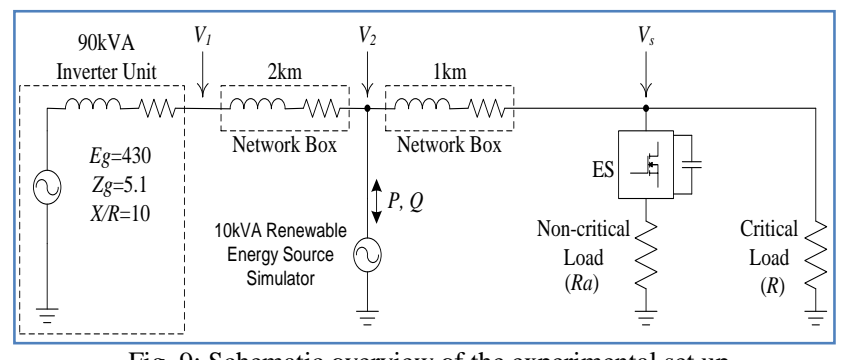

Fig. 9: Schematic overview of the experimental set up
Table II Detail Electric Spring Specification

\begin{tabular}{|l|l|}
\hline \multicolumn{2}{|c|}{ Electric Spring Power Circuit } \\
\hline Inverter Topology: & Single Phase Half Bridge Inverter \\
\hline Switching Frequency: & $20 \mathrm{kHz}$ \\
\hline Regulated DC-Bus Voltage: & $400 \mathrm{Vdc}$ \\
\hline DC Bus Capacitance: & $\mathrm{C} 1=3000 \mu \mathrm{F}, \mathrm{C} 2=3000 \mu \mathrm{F}$ \\
\hline Inverter Output Voltage Range: & $\begin{array}{l}0 \sim 134 \mathrm{Vac}, \\
\text { Controlled by the Modulation Index }\end{array}$ \\
\hline Power MOSFET: & IRFP31N50L \\
\hline Typical R $\mathrm{DS}_{\mathrm{D}(\mathrm{on})}:$ & $0.15 \Omega @ \mathrm{I}_{\mathrm{D}}=31 \mathrm{~A}$ \\
\hline Output Low Pass Filter: & \\
\hline Measured Inductance: & $500 \mu \mathrm{H} @ 100 \mathrm{~Hz}$ \\
\hline $\begin{array}{l}\text { Measured Equivalent Series } \\
\text { Resistance: }\end{array}$ & $3 \Omega @ 100 \mathrm{~Hz}$ \\
\hline Capacitance: & $13.2 \mu \mathrm{F}$ \\
\hline
\end{tabular}

\begin{tabular}{|l|c|c|c|}
\hline \multicolumn{4}{|c|}{ NI Embedded Controller } \\
\hline Switching Scheme: & Sinusoidal PWM \\
\hline $\begin{array}{l}\text { Minimum to } \\
\text { Maximum duty-cycle: }\end{array}$ & $0.05 \sim 0.95$ & & \\
\hline $\begin{array}{l}\text { Proportional and } \\
\text { Integral Controller }\end{array}$ & $\begin{array}{c}\text { Sampling } \\
\text { Time }\left(\mathrm{T}_{\mathrm{s}}\right)\end{array}$ & $\begin{array}{c}\text { Proportional } \\
\text { Gain }\left(\mathrm{K}_{\mathrm{p}}\right)\end{array}$ & $\begin{array}{c}\text { Integral Gain } \\
\left(\mathrm{K}_{\mathrm{p}} \mathrm{K}_{\mathrm{i}} / \mathrm{T}_{\mathrm{s}}\right)\end{array}$ \\
\hline AC line Control Loop: & $20 \mathrm{~ms}$ & 30 & 5 \\
\hline DC bus Control Loop: & $20 \mathrm{~ms}$ & 20 & 1 \\
\hline
\end{tabular}

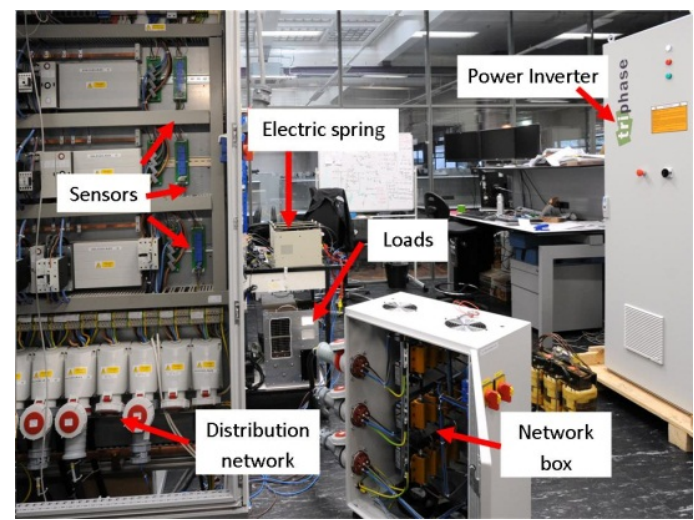

Fig. 10: Photograph of the experimental set up with major components shown

Three case studies were conducted to illustrate the operation of the ES and validate the model against experimental results. Firstly, the line voltage (i.e. voltage across the critical load) is decreased by increasing the reactive power consumption of the intermittent source and thereby, operating the ES in voltage support mode. Secondly, the line voltage is increased by decreasing the reactive power consumption of the intermittent source and thereby, operating the ES in voltage suppression mode. Finally, the reactive power absorption/injcetion by the intermittent source was varied randomly to test the voltage regulation capability of the ES and also validate its model by comparing the simulated response against the experiments. The three case studies are discussed in the following subsections.

\section{A. Step Increase in Absorbed Reactive Power: Voltage Support Mode}

In order to illustrate the voltage support capability of the $\mathrm{ES}$, the reactive power consumed by the intermittent source was increased from 467 to 1100 Var at $\mathrm{t}=2.0 \mathrm{~s}$. Without ES, this results in a reduction in line voltage below its nominal value of $220 \mathrm{~V}$, as can be seen from the blue (solid) traces in both simulated response in Fig. 11(a) and experimental results in Fig. 11(b). However, with ES, the line voltage is quickly 
restored back to its nominal value as observed both in simulation and experimental results.

In order to restore the line voltage back to its nominal value, the voltage of the ES increases from its near-zero value to about $120 \mathrm{~V}$ in the experiment results shown in Fig. 12(b). On the other hand, in the simulated response the ES voltage goes up to almost $140 \mathrm{~V}$. This difference between the simulated and experimental results is due to existence of multiple solutions to ES voltage in order to obtain the same value of the line voltage. The convergence to a particular ES voltage would depend on both the control loops for line voltage and DC link voltage regulation. Since the latter is neglected in the model, there is a discrepancy between the simulation and experimental results as hinted in Section III.

The voltage across the non-critical load is plotted in Fig.s 13(a) and 13(b). Without ES, the simulation experimental results are almost identical as expected. With ES, there is an offset between those due to the same reason explained earlier. The difference between the blue (solid) and green (dotted) traces before $t=2.0 \mathrm{~s}$ is due to the additional voltage drop in the output filter (shown in Fig. 2) of the ES.

\section{B. Step Reduction in Absorbed Reactive Power: Voltage Suppression Mode}

To test the voltage suppression capability of the ES, an increase in line voltage was caused by reducing the reactive power consumed by the intermittent source from 467 to 110 Var at $t=2.0 \mathrm{~s}$. Without ES, this results in an increase in line voltage above its nominal value of $220 \mathrm{~V}$ as is seen from the blue (solid) traces in both simulated response in Fig. 14(a) and experimental results in Fig. 14(b). However, with ES, the line voltage is quickly suppressed back to its nominal value as observed both in simulation and experimental results. In order to suppress the line voltage back to its nominal value, the voltage of the ES increases from its near-zero value to about $130 \mathrm{~V}$ in the experiment results shown in Fig. 15(b). On the other hand, in the simulated response the ES voltage goes up to almost $140 \mathrm{~V}$. As in the voltage support mode, this difference between the simulated and experimental results is due to the non unique solution of ES voltage to regulate to a fixed line voltage and neglecting the DC link voltage control loop in the model. This was explained earlier in Section V-A.

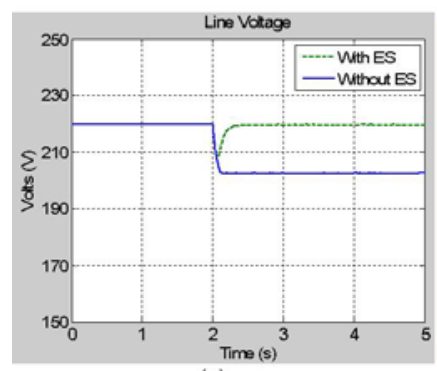

(a)

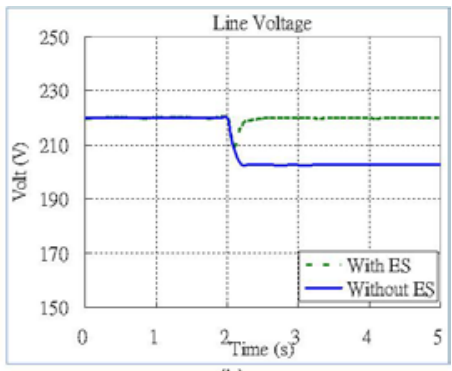

(b)
Fig. 11: Comparison between line voltages with ES operating in voltage support mode. Reactive power consumption of the intermittent source is increased from 467 to 1100 Var at $t=2.0 \mathrm{~s}$ (a) simulated response and (b) experimental results.

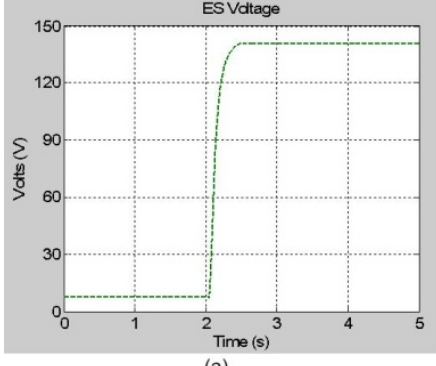

(a)

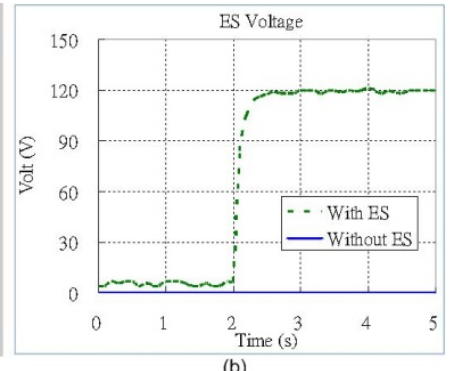

(b)
Fig. 12: Comparison between voltages injected by the ES. Reactive power consumption of the intermittent source is increased from 467 to 1100 Var at $\mathrm{t}=2.0 \mathrm{~s}$ (a) simulated response and (b) experimental results
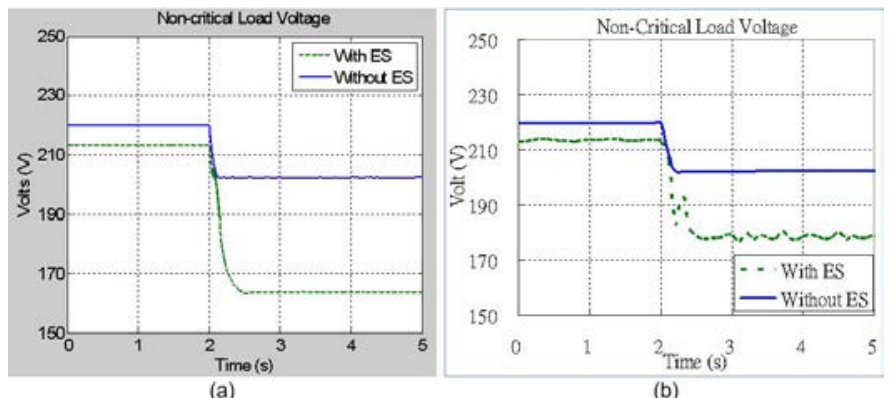

(a)

(b)

Fig. 13: Comparison between voltages across the non-critical load. Reactive power consumption of the intermittent source is increased from 467 to 1100 Var at $\mathrm{t}=2.0 \mathrm{~s}$ (a) simulated response and (b) experimental results
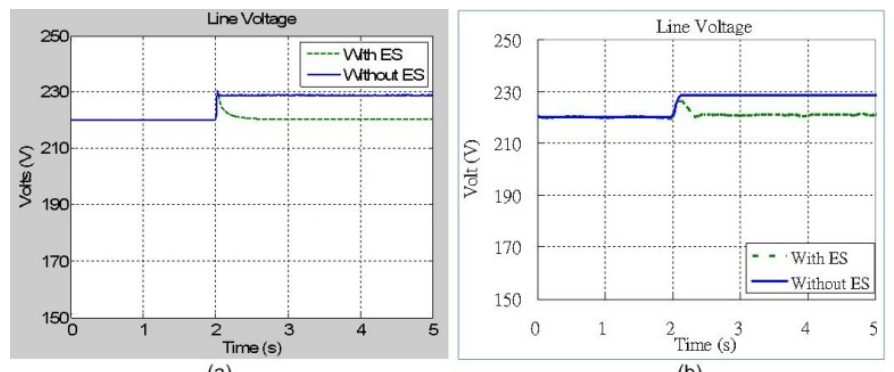

Fig. 14: Comparison between line voltages with ES operating in voltage suppression mode. Reactive power consumption of the intermittent source is reduced from 467 to 110 Var at t=2.0 s (a) simulated response and (b) experimental results
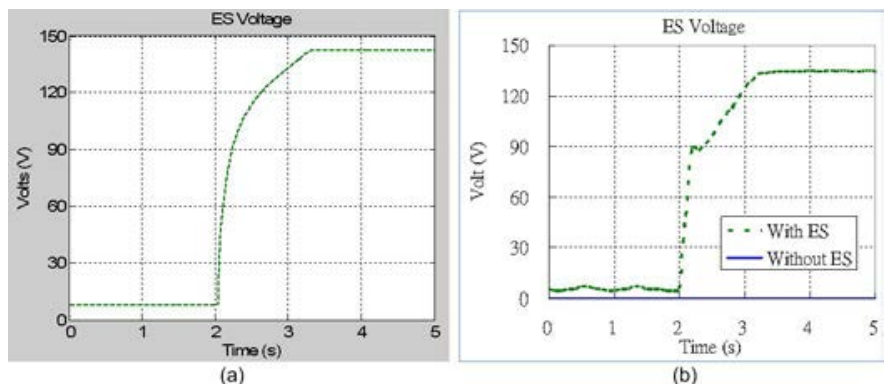

Fig. 15: Comparison between voltages injected by the ES. Reactive power consumption of the intermittent source is reduced from 467 to 110 Var at $\mathrm{t}=2.0 \mathrm{~s}$ (a) simulated response and (b) experimental results 

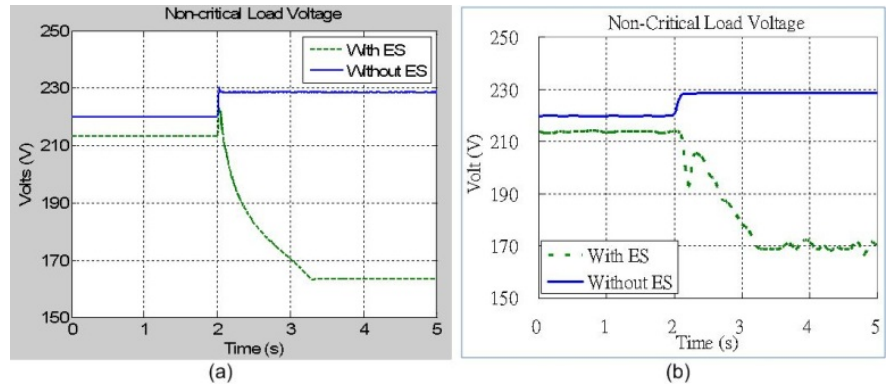

Fig. 16: Comparison between voltages across the non-critical load. Reactive power consumption of the intermittent source is reduced from 467 to 110 Var at $\mathrm{t}=2.0 \mathrm{~s}$ (a) simulated response and (b) experimental results

The voltage across the non-critical load is plotted in Figs. 16(a) and 16(b). Without ES, the simulation experimental results are almost identical as expected. With ES, there is an offset between those due to the same reason explained earlier. The difference between the blue (solid) and green (dotted) traces before $t=2.0 \mathrm{~s}$ is due to the additional voltage drop across the output filter of the ES.

The variation in active power consumed by the critical and non-critical load is shown in Figs 17(a) and 17(b).
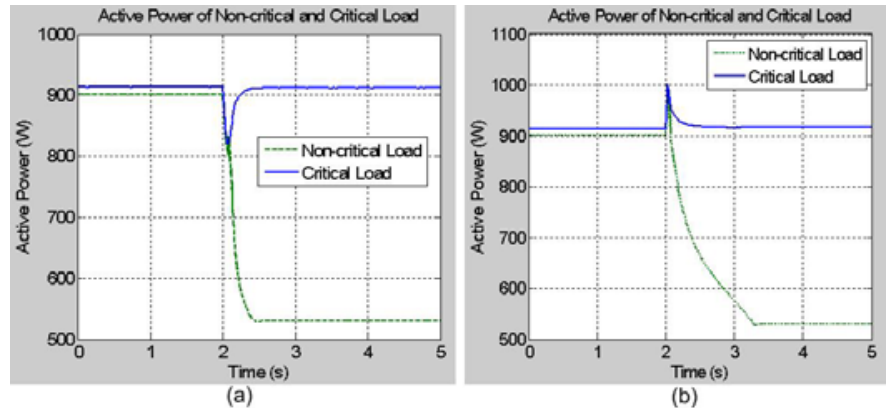

Fig. 17: Variation of active power consumeb by the non-critical and critical loads under voltage support (subplot a) and suppression (subplot b) modes

As both the loads are resitive, the active power variation is similar to that of the voltages across the loads as shown before. It can be seen that in both voltage support (subplot a) and voltage suppression (subplot b) modes, the active power consumed by the non-critical load decreseas while that across the critical load remains constant as the voltage is tighly regulated. A rigorous analytical treatment of the active and reactive power balance among an ES, critical and non-critical load is provided in [14].

\section{Random Variations in Reactive Power Injected/Absorbed}

To substantiate the voltage regulation capability of the ES, random variation in line voltage was caused by varying the reactive power consumed by the intermittent source between 110 and 1100 Var. At the same time the active power generation was also varied randomly between 130 and $270 \mathrm{~W}$. The same disturbance profile is repeated between $t=0$ to $t=$ $720 \mathrm{~s}$ and $t=720$ to $t=1440 \mathrm{~s}$. The simulated responses are shown in Fig. 18.

The ES is activated at $t=720 \mathrm{~s}$. From $t=0$ to $t=720 \mathrm{~s}$, the variations in the line voltage (which is the same as the voltage across the non-critical load in absence of ES) is clear. However, after the ES is activated at $t=720 \mathrm{~s}$, the line voltage shown in blue (solid) is tightly regulated. The variations in voltage across the non-critical load (green) (which is different from the line voltage when the ES is activated) and the voltage injected by the ES (red) is also shown between $t=0$ and $t=720 \mathrm{~s}$.

The experimental results following identical disturbance profile as above are shown in Fig. 19. As before, the line voltage is seen to be tightly regulated after the ES is activated at $t=720 \mathrm{~s}$. Moreover, the variations in voltage injected by the ES and that across the non-critical load are very similar to the simulated responses in Fig. 18. The subtle differences between the simulation and experimental results are due to the same reasons discussed earlier in Sections IV-A and IV-B.

The results presented above confirm two points: 1 . Electric spring is capable of regulating the line voltage tightly and 2 . Simulated and experimental results are very similar confirming the accuracy of the proposed ES modeling approach for use in large-scale system level studies.

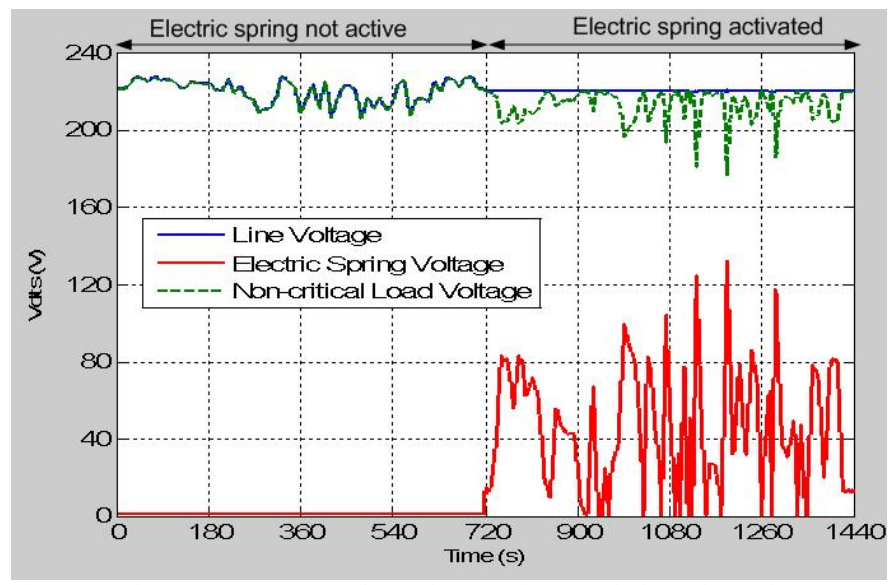

Fig. 18: Simulated response following random variations in active power generation and reactive power consumption of the intermittent source. ES is activated at $\mathrm{t}=720 \mathrm{~s}$

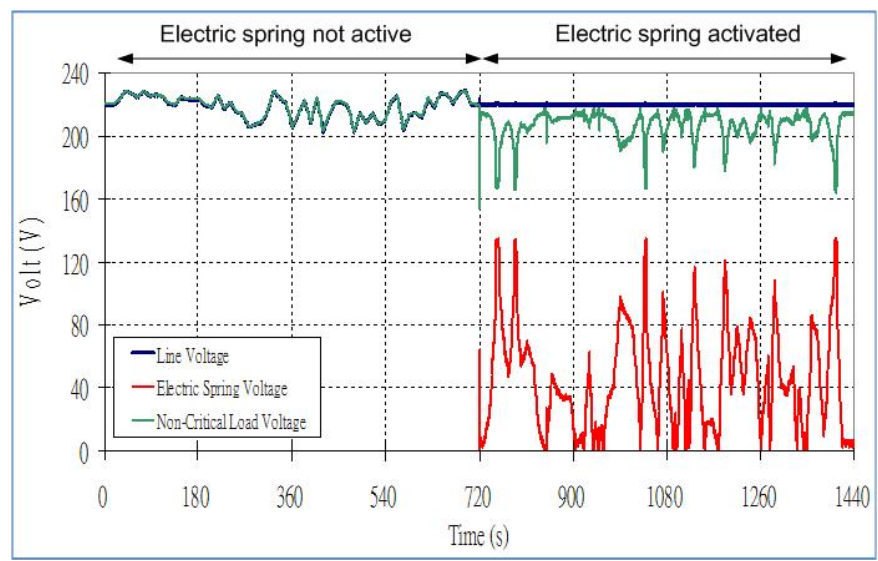

Fig. 19: Experimental results following random variations in active power generation and reactive power consumption of the intermittent source. ES is activated at $\mathrm{t}=720 \mathrm{~s}$

In order to confirm the validity of the dynamic model of the ES under different load power factors the following exercise was undertaken. The power factor of both the critical and noncritical loads was varied between 0.9 (lagging) to 1.0. The voltage regulation performance of the ES was checked for both under-voltage (i.e. ES in voltage supporting mode) and over-voltage (i.e. ES in voltage suppression mode) conditions. 
The dynamic model of the ES (described in Section IV) was found adequate to simulate the performance under different load power factors. A representative case is shown in Fig. 20 for a power fator of 0.95 (lagging) for both critical and noncritical load. The same variations in active and recative power injection by the intermitten source as in the cases of Fig. 18 was considered here with the ES activated after $t=720 \mathrm{~s}$.

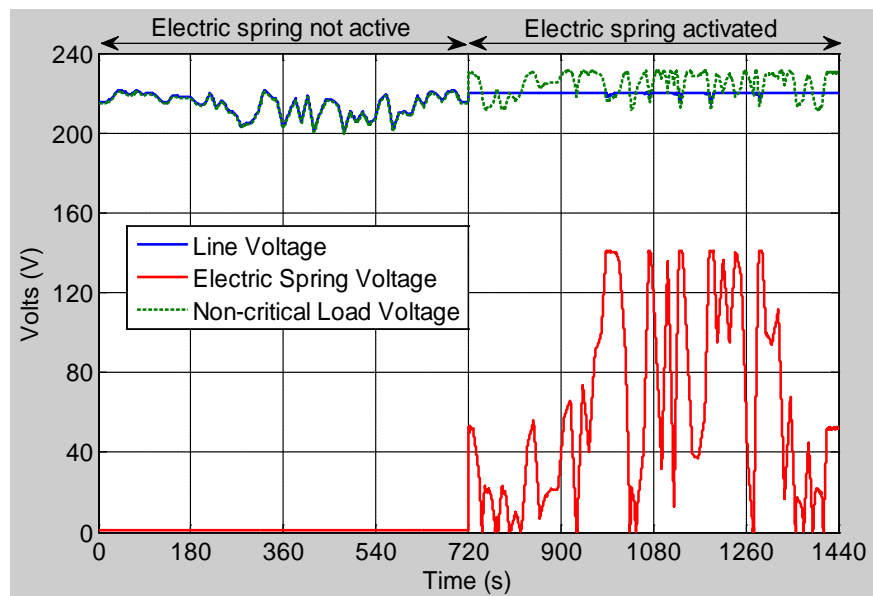

Fig. 20: Simulated response for RL load (both critical load and non-critical load) with a power factor of 0.95 lagging following random variations in active power generation and reactive power consumption of the intermittent source. $\mathrm{ES}$ is activated at $\mathrm{t}=720 \mathrm{~s}$

It can be seen that the line voltage (blue trace) is tightly regulated after that due to variations in the voltage injected by the ES (red trace). In this case the peak variation of the ES voltage is larger than that in Fig. 18 which can be attributed to higher reactive consumption by the RL loads than the purely resistive loads used before. Also as the voltage across the noncritical load and that injected by the ES do not have to be in quadrature (as in the case of restive loads) the spikes in noncritical load voltage (green trace) are less prominent in this case.

\section{PROPORTION OF CRITICAL AND NON-CRITICAL LOADS}

The proportion of the critical and non-critical load is important towards the effectiveness of an ES both in terms of its voltage regulation and reactive capability. The reactive capability of an ES is governed by the product of the voltage it injects and the current flowing through it (which is the same as the current through the non-critical load). If the injected voltage increases, the voltage across the non-critical load and hence the non-critical load current reduces which limits the reactive capability of an ES and thus its ability to regulate the voltage across the critical load. For a low proportion of noncritical load, the fidelity of the current is restricted which limits the capability of an ES compared to the case when the proportion of non-critical load is relatively high. To verify this, simulations were conducted with different proportions of non-critical (NC) and critical (C) loads. The results are shown in Fig. 21.

It can be seen that for high proportion of non-critical load (NC:C=9:1) shown by the blue traces, the critical load voltage is restored back to its nominal value, with only $80 \mathrm{~V}$ injected by the ES. This results in little change (from $216 \mathrm{~V}$ to $202 \mathrm{~V}$ ) in voltage across the non-critical load. Voltage regulation is similar for equal proportion of critical and non-critical (NC:C=5:5) loads shown by green traces. However, the voltage across the non-critical load is lower (about $140 \mathrm{~V}$ ) than before due to larger injected voltage $(160 \mathrm{~V})$ by the ES.

For low proportion of non-critical load (NC: $\mathrm{C}=1: 9$ ), it is not possible to restore the voltage across the critical load back to its nominal value as shown by the red trace on top-right subplot. This demonstrates that the voltage regulation capability of an ES is dependent on the relative proportion of non-critical and critical load. Lesser the proportion of noncritical load, lower is the voltage regulation capability of an ES. This limitation does not necessarily apply for the second generation of ES with embedded energy storage which is beyond the scope of this paper. According to a government report [17], the non-critical load (for air conditioning systems, refrigerators and water heating systems) accounts for about $52 \%$ of the total energy consumption in the residential sector.
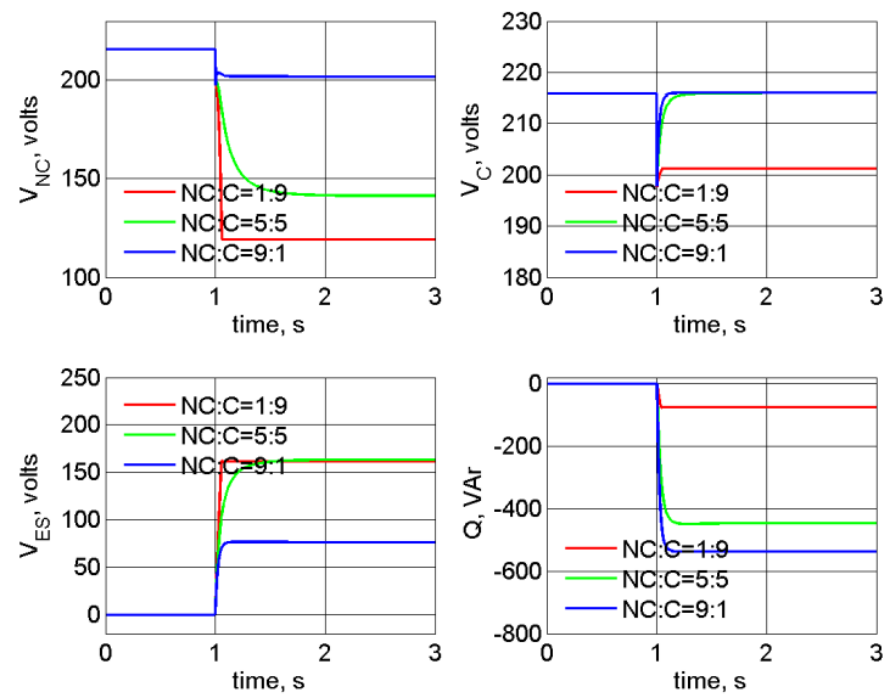

Fig. 21: System response for different distribution of non-critical and critical loads (NC:C). Disturbance is increase in reactive power consumption of the intermittent source from 467 to $1100 \mathrm{VAr}$ at $\mathrm{t}=1.0 \mathrm{~s}$

\section{CONCLUSION}

The electric spring is a new technology that has attractive features including dynamic voltage regulation, balancing power supply and demand [8,9], power quality improvement [14], distributed power compensation [15] and reducing energy storage requreiments for future smart grid [16]. In order to fully explore their full potentials in large-scale power system simulation, an averaged simulation model for the electric spring is proposed here for the smart grid research community. The simulation model is simple for inclusion into large-scale system simulation platforms and yet accurate enough to capture the dynamic behavior of interest in terms of studying voltage and frequency stability. The case studies reported in the previous section exhibited close match between simulation and experimental results confirming the accuracy. The discrepancies, wherever applicable have been accounted for. These are due to the fact that the DC link voltage control loop has been neglected. This results in attaining a different operation point in terms of ES voltage in 
order to obtain the same line voltage which is possible as suggested by the phasor diagrams in Fig. 3 . It is possible, of course, to include the DC link voltage control loop in the model to eliminate these little discrepancies but only at the expense of significant increase in simulation time for large systems. The addition of DC link voltage control loop (with large number of ES distributed across the system) makes the simulation much more complex with little improvement in terms of accuracy.

The use of 'Electric Springs' is a novel way of distributed voltage control while simultaneously achieving effective demand-side management through modulation of non-critical loads in response to the fluctuations in intermittent renewable energy sources (e.g. wind). This paper describes the simulation approach for electric springs which is appropriate for voltage and frequency control studies at the power system level. Close similarity between the simulation and experimental results gave us the confidence to use this electric spring model for investigating the effectiveness of their collective operation when distributed in large number across a power system. The proposed dynamic model is generic enough to study the performance of ESs under different load power factors and proportion of critical and non-critical loads. The effectiveness of an ES improves with the proportion of non-critical load.

\section{ACKNOWLEDGMENT}

The authors would like to thank their colleagues at the Maurice Hancock Laboratory, Imperial College London for their help in setting up the experiment.

\section{REFERENCES}

[1] P. Palensky and D. Dietrich, "Demand Side Management: Demand Response, Intelligent Energy Systems, and Smart Loads," IEEE Transactions on Industrial Informatics, vol. 7, pp. 381-388, 2011.

[2] A. Brooks, E. Lu, D. Reicher, C. Spirakis, and B. Weihl, "Demand Dispatch," IEEE Power and Energy Magazine,, vol. 8, pp. 20-29, 2010.

[3] D. Westermann and A. John, "Demand Matching Wind Power Generation With Wide-Area Measurement and Demand-Side Management," IEEE Transactions on Energy Conversion, vol. 22, pp. 145-149, 2007

[4] A. Mohsenian-Rad, "Autonomous Demand-Side Management Based on Game-Theoretic Energy Consumption Scheduling for the Future Smart Grid," IEEE Transactions on Smart Grid, vol. 1, pp. 320-331, 2010.

[5] S. C. Lee, "Demand Side Management With Air Conditioner Loads Based on the Queuing System Model," IEEE Transactions on Power Systems, vol. 26, pp. 661-668, 2011.

[6] M. Parvania and M. Fotuhi-Firuzabad, "Demand Response Scheduling by Stochastic SCUC," IEEE Transactions on Smart Grid, vol. 1, pp. 8998, 2010.

[7] M. Pedrasa, "Scheduling of Demand Side Resources Using Binary Particle Swarm Optimization," IEEE Transactions on Power Systems, vol. 24, pp. 1173-1181, 2009.

[8] S. Y. R. Hui, C.K. Lee and F. Wu, "Power control circuit and method for stabilizing a Power Supply," PCT patent application vol. 61/389,489, filed on 4 October 2010.

[9] S.Y.R. Hui, C.K. Lee and F. Wu, "Electric springs - A new smart grid technology," IEEE Transactions on Smart Grid, Vol.3, No.3, Sept., 2012, pp:1552-1561.

[10] S. R. Sanders, "Generalized averaging method for power conversion circuits," Power Electronics, IEEE Transactions on, vol. 6, pp. 251-259, 1991.

[11] N. G. Hingorani and L. Gyugyi, Understanding FACTS : concepts and technology of flexible AC transmission systems. New York: Institute of Electrical and Electronics Engineers, 1999.
[12] T. J. E. Miller, Reactive power control in electric systems. New York ; Chichester: Wiley, 1982.

[13] J. Dixon, L. Morán, J. Rodríguez and R. Domke, "Reactive Power Compensation Technologies: State-of-the-Art Review," Proceedings of the IEEE, vol. 93, pp. 2144-2164, 2005.

[14] S. C. Tan, C. K. Lee, and S.Y.R. Hui, "General Steady-State Analysis and Control Principle of Electric Springs With Active and Reactive Power Compensations," IEEE Transactions on Power Electronics, vol. 28, Issue: 8, pp. 3958-3969, 2013.

[15] C.K. Lee, N. Chaudhuri, B. Chaudhuri and S.Y.R. Hui, "Droop Control of Electric Springs for Distributed Stability Support of Smart Grid", IEEE Transactions on Smart Grid, vol. 4, no. 3, pp. 1558 - 1566, 2013

[16] C.K. Lee and S.Y.R. Hui, "Reduction of Energy Storage Requirements in Future Smart Grid Using Electric Springs", IEEE Transactions on Smart Grid, vol 4, no. 3, pp. 1282 - 1288, 2013

[17] Electrical \& Mechanical Services Department, HKSAR Government, “Hong Kong Energy End-Use Data 2013”, September 2013, pp: 22. 